\title{
Selaginella densa reflectance: Relevance to rangeland remote sensing
}

\author{
MRYKA HALL-BEYER, AND Q. HUGH J. GWYN
}

\author{
Authors may be contacted at the Centre d'applications et de recherche en télédétection (CARTEL), Université de \\ Sherbroake, 2500, Boul. Université Sherbrooke, Québec JIK 2RI, Canada.
}

\begin{abstract}
Selaginella densa Ryd. is a shallow-rooted spikemoss that grows on sparsely vegetated short and mid-grass prairie. It covers a proportion of bare soil which may rival that covered ${ }^{\prime} b y$ grasses. Not a forage plant, it is treated in agronomic research as background to the edible plants. Even when it appears to the eye as dry and without active chlorophyll, its spectral reflectance resembles more closely that of forage plants than that of soil background. It is distinguishable from dense stands of chlorophyll-rich forbs and grasses using the normalized differential vegetation index, but $S$. densa in all cases resembles sparse grasses. Its presence must be considered when estimating range condition using remote sensing techniques.
\end{abstract}

Key Words: remote sensing, clubmoss, reflectance, midgrass prairie

Various small soil-covering plants contribute to measured reflectance in remote sensing studies, but cannot be separated from plants that are the object of research interest. Mosses and lichens have been explicitly lumped with soil background in rangeland (Jaques, 1982) and shrubland (Graetz and Gentle 1982). Smith et al. (1990) noted the effects of lichen on desert soil reflectance. Studies of lichens themselves are limited to a different ecozone: Vogelman and Moss (1994) examined the spectral reflectance of Sphagnum sp., which contributes to the signal received from boreal forest areas. Sims (1983) looked at arctic caribou rangeland. Tueller $(1989,1992)$ repeatedly pointed out the need to study these lichens.

Selaginella densa Ryd., commonly called "little clubmoss", is a member of the fern phylum. It forms a mat-like covering on prairie soils, and occasionally on dry, usually calcareous, rocks (Looman and Best 1987; Vitt et al. 1988). The plant is only a few centimeters tall, and its matlike geometry is such that it casts no shadows. On dry prairie, $S$. densa may cover as much soil as do the various grass species. The basal area of $S$. densa has been measured at $6.5 \%$ in the Stipa-Bouteloua faciation, where total vegetation cover is only $12.2 \%$ (Smoliak et al. 1990). It maintains a very shallow root system, enabling it to respond rapidly to infrequent rainfall and to dry rapidly after using available surface

This data was gathered during an ongoing study supported by Parks Canada, Resource Conservation Service.

Manuscript accepted 21 Jan. 1996 moisture. It is usually dry during cloudless weather when satellite images are acquired. Because it is not eaten by domestic stock, $S$. densa is rarely mentioned in rangeland studies, and then only as possibly inhibiting either grass establishment or erosion (Coupland 1950).

A proportion of the reflectance of grassland and cropland results from non-plant surfaces. To distinguish between plant and background, various vegetation indices rely on a high reflectance from chlorophyll in near infrared wavelengths and corresponding high absorption in visible wavelengths. Since dry $S$. densa does not appear to contain active chlorophyll, its reflectance pattern might be presumed to resemble that of non-plant material. If this is the case, remote sensing could treat $S$. densa as background to the plants of interest, as does agronomy. The questions are: Do spectral measurements see $S$. densa as vegetation or as soil? If the latter, does its spectrum differ from typical soils in any recognizable way? If the former, can it be distinguished spectrally from forage grasses and forbs or from senescent vegetation? Finally, how can results from this study using a small instrument footprint of $16 \mathrm{~cm}$ be extrapolated to typical satellite sensor footprints of from 10 to $80 \mathrm{~m}$ ?

\section{Methods}

Measurements were taken in the field over a period of several days in late July, 1993, on northern midgrass prairie in Grasslands National Park, Saskatchewan, Canada. All measurements were made between 1100 and 1330 hours on cloudless days. An Exotech radiometer (model 100BX-T, Exotech Inc., Gaithersburg, Md.) measured reflected light using filters simulating both Multispectral Scanner (MSS) bands 1 to 4 and Thematic Mapper (TM) bands 1 to 4 . The sensor was fixed at a height of 60 cm viewing vertically; the $15^{\circ}$ view angle targets a circle $16 \mathrm{~cm}$ across. An eyepiece allows visual pinpointing of the target. Reflectance was calculated using a $\mathrm{BaSO}_{4}$ reference surface.

Percentages of green material in $S$. densa clumps were estimated visually and divided into 3 classes: $<20 \%$ green $20-40 \%$ green, and $>40 \%$ green. All clubmoss clumps contained much senescent material, and none had more than $60 \%$ green surface. Reflectance was measured of live and dead grasses ((Agropyron cristatum (L.) Gaertn.) alone, both green and dry; A. dasystachyum (Hook.) Scribn., Bouteloua gracilis (HBK.) Lag.), and Stipa comata Trin. \& Rupr., separately and mixed); of bare soil; of sparse grasses growing on bare soil; and of several forbs. $A$. cristatum, an introduced species, almost always occurs in nearly 
pure, dense seeded stands. Field of view was selected so that no material other than the target plant(s) themselves, or soil where indicated, was present.

The study area soil is a Chernozem (dry brown subdivision) according to Canadian soils nomenclature. The United States system would call it Mollisol (Boehm 1992). These soils do not have the high iron sesquioxide content that creates problems with vegetation indices due to its red reflectance (Huete and Tucker 1991).

\section{Results}

Figures 1 and 2 show $S$. densa spectral reflectance $(\mathrm{N}=27)$, at sites where $S$. densa occupied the entire field of view. There are no significant differences ( $\alpha=0.05$ ) among any of the greenness groups in any of the bands. In all cases the mean for all $S$. densa measurements can be taken as representative.

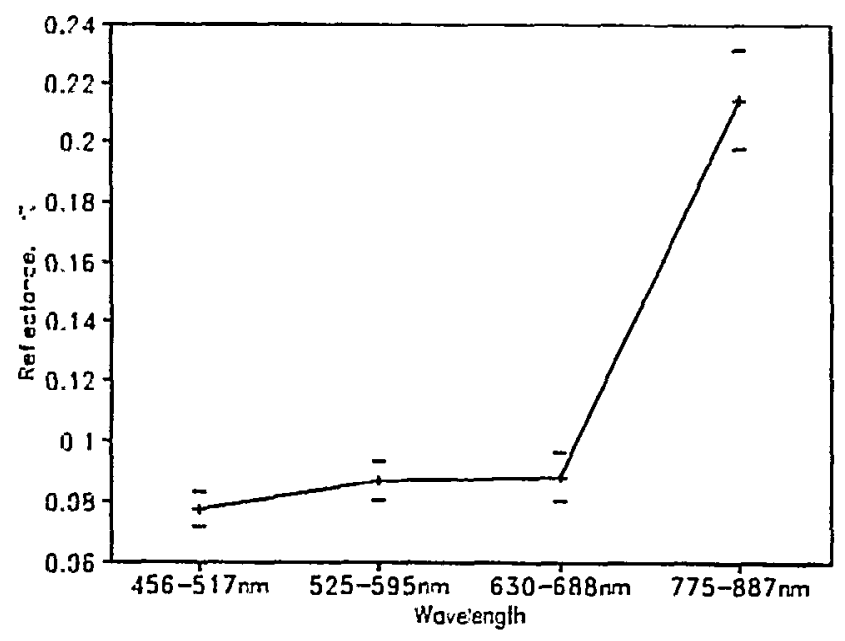

Fig. 1. Mean and 1 std dev, all $S$. densa measurements

Figure 3 compares $S$. densa with pure stands (no bare soil) of several other plants, and with bare soil. Compared to the highchlorophyll actively growing grass and forbs, $S$. densa shows lower band 4 reflectance, as expected. However, $S$. densa's

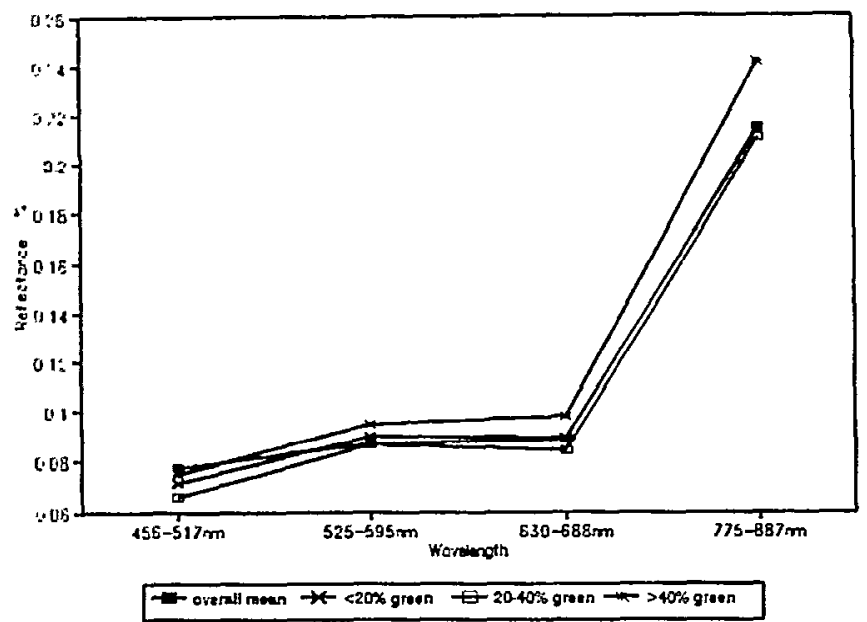

Fig. 2. S. densa by percent area of green material

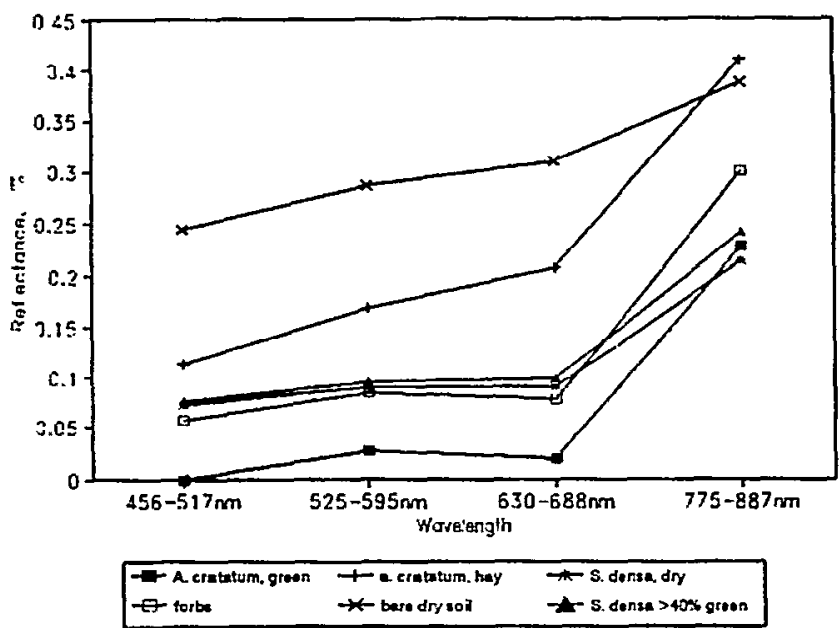

Fig. 3. Comparison of $S$. densa with soil and complete covers

reflectance in bands 2 and 3 resembles these green plants much more closely than it resembles the senescent grass or bare soil. Thus we would predict that using ratio vegetation indices, all $S$. densa should be distinguishable from both dry plants and from bare soil. The index comparisons presented in Figures 5 and 6 confirm this. Thus we have the answer to the first question posed above: spectral measurements see $S$. densa as part of the vegetation rather than as low-brightness soil. It may also be distinguished from dense stands of senescent vegetation (hay).

Figure 4 compares $S$. densa reflectance to that which would be observed in typical rangeland situations, namely soil partially covered by various grasses and forbs. None of the targets included S. densa. The graph presents means of between 5 and 10 observations of each type; plant cover ranges from 10 to $20 \%$ of soil surface area. The lush green forbs are distinguished, even as partial cover, by high reflectance in band 4 . No readings were obtained of partial cover of very green grass: in late July, even in rain-soaked 1993, the only lush green grass is in seeded and irrigated fields, where it completely obscures the soil. There is no difference in spectral pattern among the grasses, nor between them and $S$. densa or lichen. The reflectances of $S$. densa plus bare soil are within a one standard deviation envelope of all $S$.

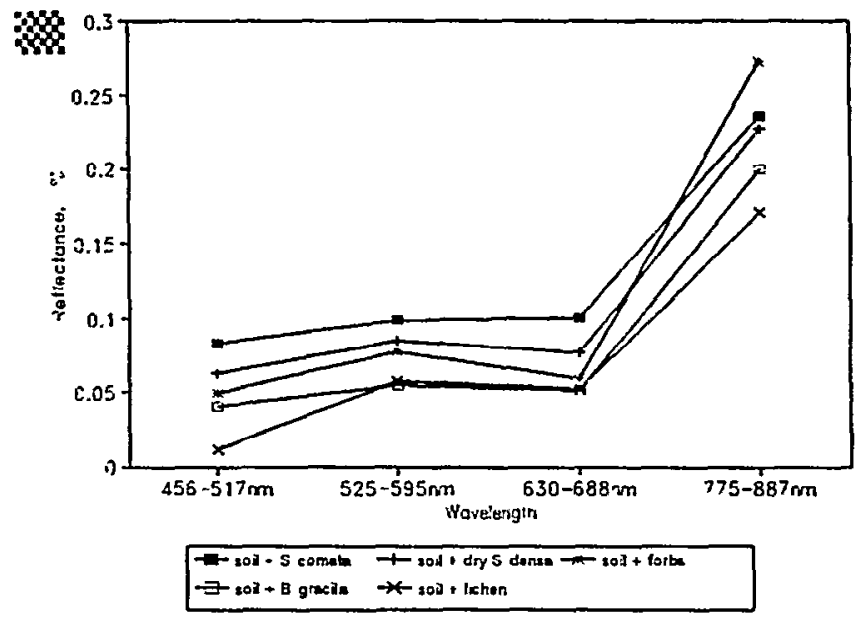

Fig. 4. Comparison of $S$. densa with incomplete soil covers 
densa measurements. From spectral reflectance alone, it would not be possible to distinguish approximately equal covers of $S$. densa and native grasses.

Vegetation indices have been developed to identify particular types of vegetation, distinguish them from other features, or extract parameters such as leaf area index and total biomass (Dusek et al. 1985). The NDVI (Normalised Difference Vegetation Index) is:

$$
N D V I=\left(R_{i}-R_{\mathrm{r}}\right) /\left(R_{i}+R_{\mathrm{r}}\right)
$$

where $\mathrm{Ri}=$ reflectance in the sensor's photographic infraredrange, band 4 for TM data

$\mathrm{Rr}=$ reflectance in the sensor's red range, band 3 for TM data

The NDVI is functionally equivalent to other ratio indices that use wavelengths of $450-900 \mathrm{~nm}$, in other words TM bands 1 through 4 (Dusek et al. 1985). In figure 5, the NDVI of $S$. densa and that of partial grass cover fall in the middle of the range of measured reflectances. As expected, bare soil has a very low NDVI value, and green grasses or forbs which cover the soil have a high NDVI value.

Vegetation indices involving linear band combinations have been developed to separate plant from soil reflectance when viewing areas having partial soil cover. The indices differ in their assumptions about the reflectance of the underlying soils. Elvidge and Lyon (1985) give a summary of these indices.

Of these linear indices, the GVI (greenness vegetation index) calculated here is the second component of the Kauth and Thomas (1976) tasselled cap transformation. It measures the perpendicular distance of a given measurement from the "soil line." This line connects variously-illuminated bare soil points in band 3 versus band 4 feature space. The slope of the soil line in Grasslands Park, determined from bare soil pixels in a Landsat 1 image, is very close to that measured by Kauth and Thomas (1976), and so their coefficients were used. A similar transformation using Thematic Mapper (TM) bands could not be produced

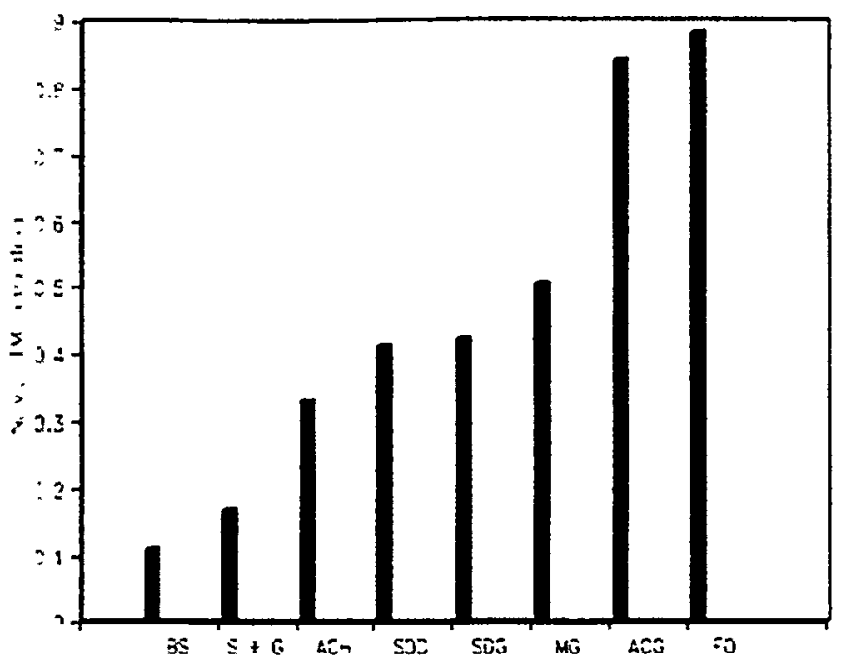

Fig. 5. NDVI of various plants. $B S=$ bare soil; $\mathbf{S}+\mathbf{G}=$ soil+very sparse grass; $\mathrm{ACH}=$ senescent Agropyron cristatum; $\mathrm{SDD}=S$. densa, '20\% green material; SDG $=S$. densa, $>40 \%$ green material; $\mathbf{M G}=$ mixed grasses + senescent material; $\mathbf{A C G}=$ lush green Agropyron cristatum; FO=green forbs

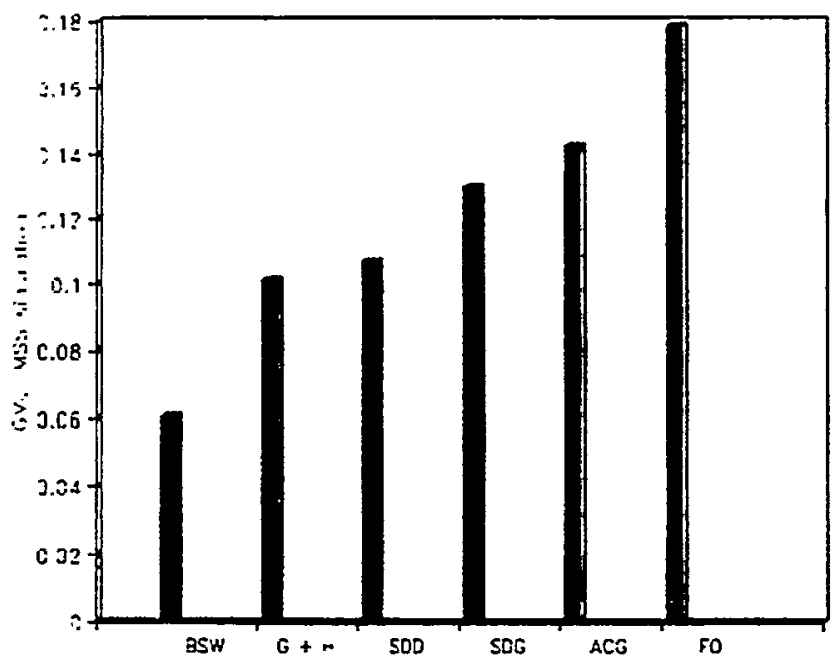

Fig. 6. GVI of various plants. BSW=bare wet soil; $\mathbf{G}+\mathrm{H}=$ mixed grasses+senescent material; $\mathrm{SDD}=S$. densa, ' $20 \%$ green material; $\mathrm{SDG}=S$. densa, $>40 \%$ green; $\mathrm{ACG}=$ lush green Agropyron cristatum; $\mathbf{F O}=$ green forbs

because the Exotech instrument used does not simulate TM bands 5 and 7. The calculated Greenness Vegetation Index values in figure 6 represent 2 readings each and should be considered tentative unless they can be replicated. Figure 6 compares Greenness Vegetation Index values for several ground covers. Once again the forbs stand out, but the Greenness Vegetation Index is less efficient than is Normalized Difference Vegetation Index at distinguishing $S$. densa from other ground covers.

\section{Discussion and Conclusions}

Both spectral reflectance and commonly used vegetation indices fail to distinguish between ground cover containing $S$. densa and common prairie grasses in late July. This study does not attempt to correlate reflectance with Leaf Area Index, but it would predict that an equal partial soil cover of grass and of $S$. densa would be indistinguishable.

Footprints of the most commonly used satellite-borne sensors range from $10 \mathrm{~m}$ for panchromatic images obtained by the French SPOT satellite, through $30 \mathrm{~m}$ for Thematic Mapper and $80 \mathrm{~m}$ for Multispectral Scanner. Typically an ordinary image would include grass and clubmoss mixed within the sensor footprint. Since pure $S$. densa and pure grass stands are not distinguishable on the basis of their spectra, these mixed pixels would not enable range managers to tell if they are looking at forage or the undesirable clubmoss. Under the condition of mixed pixels, the only way to extract the required information is to model the typical pixel (Woodcock and Strahler 1987). This requires knowledge of the percent ground surface occupied by the species in question. While this has been done for the forage species at various range sites and conditions, range studies have not systematically collected the ground cover percents of $S$. densa at the various range sites.

Most remote sensing studies of grasslands use reflectance and values derived from it to classify areas according to biomass for grazing management (Hanson et al. 1992; Tueller 1989 and 1992). This method assumes that the biomass present is composed of forage species. S. densa is not eaten by ruminants; it 
may be removed by trampling. S. densa increases under light grazing as opposed to either heavy grazing or no grazing (Smoliak 1965). As long as $S$. densa can be treated as background to plants of agricultural interest, these scattered reports provide all the information necessary. However, if reflectance, usually from satellite imagery, is to be a surrogate for biomass, and $S$. densa reflects as sparse grass, more needs to be known about the occurrence and abundance of clubmoss. Only with information on typical $S$. densa ground cover by range site and condition could satellite images be used for an accurate estimation of grasses of use to domestic livestock. Of course, the same problem exists in relation to unpalatable grasses and herbs, but this question has been addressed (though not entirely solved) in range studies. Range managers have some idea of the proportions of such plants expected on different sites (Abouguendia 1993). They do not have similar knowledge of $S$. densa proportions.

When using remotely sensed data to estimate green biomass, range condition or leaf area index, the possible presence of $S$. densa must be taken into account. On some sites, nearly half of the vegetation reflectance may be produced by clubmoss. Studies that use optical remote sensing data to classify range condition and biomass should acquire data on the presence and percent basal cover of $S$. densa as part of ground truth. More generally, estimates of expected percent $S$. densa ground cover under various grazing regimes and in various range sites would be useful. Failure to consider $S$. densa can lead to overestimation of usable biomass when these estimates are derived from reflectance measurements.

\section{Literature Cited}

Abouguendia, Z.M. 1993. Common Plant species found on selected range sites in southwestern Saskatchewan. Extension Service, Saskatchewan Rural Devel. Serv., Swift Current, Sask..

Boehm, M. 1992. Soils of Grasslands National Park, Saskatchewan. Parks Canada, Prairie and Northern Region, Winnipeg, Man.

Coupland, R.T. 1950. Ecology of Mixed Prairie of Canada, Ph.D. thesis, Univ. of Nebraska, Lincoln, Nebr.

Dusek, D.A., R.D. Jackson, and J.T. Musik. 1985. Winter wheat vegetation indices calculated from combinations of seven spectral bands. Rem. Sens. Environ. 18:255-267.

Elvidge, C.D. and R.J. Lyon. 1985. Influence of rock-soil spectral variation on the estimation of green biomass, Rem. Sens. Environ. 17:265279.

Graetz, R.D. and M.P. Gentle. 1982. The relationship between reflectance in the Landsat wavebands and the cover on Australian semi-arid shrub rangeland, Photog. Eng. and Rem. Sens. 48:17211730.

Hanson, J.D., G.L. Anderson, and R.H. Haas. 1992. Combining remote sensing techniques with simulation modelling for assessing rangeland resources. Geocarto Int. 7,1:99-104.

Huete, A.R., and C.J. Tucker. 1991. Investigation of soil influences in AVHRR red and near-infrared vegetation index imagery. Int. J. Remote Sensing. 12, 6:1223-1242.

Jaques, D.R. 1982. Grassland biomass estimation and range condition analysis using Landsat imagery in fescue grasslands of western Canada, Alberta Remote Sensing Centre Pub 82-4.

Kauth,R.J., and G.S. Thomas. 1976. The tasselled cap: a graphical description of spectral-temporal development of agricultural crops as seen by Landsat. Proc. Symposium on Machine Processing of Remote Sensing Data, West Lafayette, Indiana: LARS: pp. 41-51.

Looman, J., and K.F. Best. 1987. Budd's Flora of the Canadian Prairie Provinces. Ottawa: Agr. Canada Pub 1662.

Sims, R.A.. 1983. Ground truth and large-scale $70 \mathrm{~mm}$ aerial photographs in the study of reindeer winter rangeland, Tuktoyaktuk Peninsula Area, NWT. Ph.D. Diss., Univ. of British Columbia.
Smith, M.O., S.L. Ustin, J.B. Adams, and A.R. Gillespic. 1990. Vegetation in deserts I: A Regional measure of abundance from multispectral images. Rem. Sens. Environ. 31:1-6

Smoliak, S. 1965. A Comparison of ungrazed and lightly-grazed StipaBouteloura prairie in southeastern Alberta. Can. J. Plant Sci. 45:270275.

Smoliak, S., W.D. Willms, and N.W. Holt. 1990. Management of Prairie Rangeland, Ottawa, Agr. Canada Pub. 1589 36pp.

Tueller, P.T. 1989. Remote sensing technology for range management applications. J.. Range Manage. 42:442-453.

Tueller, P.T. 1992. An overview of remote sensing for range management. Geocarto Internat. 7:5-10.

Vogelman, J.E., and D.M. Moss. 1993. Spectral reflectance measurements of the genus Sphagnum. Rem. Sens. Env. 45:273-279.

Vit, D.I., J.E. March, and R.B. Bovey. 1988. Mosses, Lichens and Ferns of Northwestern North America. Lone Pine Press, Edmonton, Alberta

Woodcock, C.E. and Strahler, A.H. 1987. The factor of scale in remote sensing. Rem. Sens. Inv. 21:311-322. 